\title{
Respostas fenológicas de cultivares brasileiras de trigo à vernalização e ao fotoperíodo
}

\author{
Tanaka Lima Parreira Ribeiro(1), Gilberto Rocca da Cunha(2), João Leonardo Fernandes Pires(2) \\ e Aldemir Pasinato(2)
}

\begin{abstract}
(1)Universidade de Passo Fundo, BR 285, Km 171, Bairro São José, CEP 99001-970 Passo Fundo, RS. E-mail: tanakaparreira@bol.com.br (2)Embrapa Trigo, Caixa Postal 451, CEP 99001-970 Passo Fundo, RS. E-mail: cunha@cnpt.embrapa.br, pires@cnpt.embrapa.br, aldemir@cnpt.embrapa.br
\end{abstract}

\begin{abstract}
Resumo - O objetivo deste trabalho foi avaliar o efeito de diferentes combinações de vernalização e fotoperíodo no desenvolvimento de cinco cultivares brasileiras de trigo. O experimento foi realizado em Passo Fundo, RS, em três épocas de semeadura: 23/6, 25/7 e 27/8 de 2003. O delineamento experimental foi o de blocos ao acaso com parcelas subsubdivididas e quatro repetições. Os tratamentos consistiram de: três regimes fotoperiódicos fotoperíodo natural (FN), fotoperíodo estendido em quatro horas (FE 4) e fotoperíodo estendido até completar vinte horas de luz (FE 20) - locados na parcela principal; dois regimes de vernalização - não vernalizado (NV) e vernalizado com 30 dias (V) -, na subparcela; e cinco cultivares de trigo - BRS 179, BRS 194, BRS 207, BRS Figueira e BRS Umbu, avaliadas nas subsubparcelas. Houve interação entre fotoperíodo e cultivar (semeadura em 23/6), e todas as cultivares tiveram o ciclo reduzido com o aumento do fotoperíodo, enquanto nas plantas com épocas de semeadura 25/7 e 27/8, houve interação entre fotoperíodo e cultivar e entre vernalização e cultivar. Essas variáveis aceleraram o ciclo de desenvolvimento da cultura e interferiram na duração dos subperíodos importantes para a formação dos componentes do rendimento de grãos.
\end{abstract}

Termos para indexação: Triticum aestivum, fenologia, genótipo.

\section{Phenological responses of Brazilian wheat cultivars to vernalization and photoperiod}

\begin{abstract}
The objective of this work was to evaluate the effects of vernalization and photoperiod on the phenological development of five Brazilian wheat cultivars. The experiment was carried out in Passo Fundo, Rio Grande do Sul state, Brazil, in three sowing dates: June 23, July 25 and August 27 of 2003. The experimental design was random block, with split split plots, and four repetitions. The treatments consisted of: three light regimes - natural photoperiod (NP), four hour day length extensions (EP 4), and an extended photoperiod of 20 hours of light per day (EP 20), in the main plot; two vernalization regimes - unvernalized (NV) and vernalized during thirty days (V) - in the split plot; and five wheat cultivars - BRS 179, BRS 194, BRS 207, BRS Figueira, and BRS Umbu - evaluated in the split split plots. There was an interaction between photoperiod and cultivar cycle for the first sowing date. For all the cultivars, the cycle was reduced with the increase of the photoperiod. However, for the second and third sowing dates, there was also an interaction between cultivars and vernalization. These variables accelerated the crop cycle, and affected the duration of important subperiods for the composition of yield grain components.
\end{abstract}

Index terms: Triticum aestivum, phenology, genotype.

\section{Introdução}

As principais variáveis do ambiente que afetam o desenvolvimento do trigo são temperatura (inclusive efeitos vernalizantes) e fotoperíodo. O trigo pode responder ao fotoperíodo, entre a emergência e o final da fase reprodutiva. Admite-se que a vernalização afeta apenas a fase vegetativa (Slafer, 1996).

A resposta à vernalização, com reflexos no processo de indução floral, depende de variáveis como: temperatura vernalizante, duração do período de vernalização, genótipo e estádio de desenvolvimento da planta. As plantas de trigo respondem à vernalização - especialmente pela diminuição do tempo para atingir o florescimento -, com a redução do número de primórdios foliares e, por consequência, com a redução do número final de folhas (Slafer \& Rawson, 1994).

O ciclo de desenvolvimento do trigo, da emergência à maturação fisiológica, pode ser dividido em três fases: vegetativa, que ocorre entre a formação dos primórdios 
foliares do colmo principal até a formação do primeiro primórdio floral; reprodutiva, que se subdivide em início da fase reprodutiva, da iniciação floral até a formação da espigueta terminal, quando todas as espiguetas e algumas flores já estão diferenciadas, e final da fase reprodutiva, que ocorre desde a iniciação da espigueta terminal até o florescimento ou antese; e fase de enchimento de grãos, que vai da antese até a maturação fisiológica (Slafer \& Rawson, 1994).

Conforme Fischer (1985), o potencial de rendimento de grãos em trigo é determinado, principalmente, no final da fase reprodutiva - etapa de alongamento do colmo, antes da antese -, quando o número de flores férteis é definido. Geralmente, entre 6 e 12 primórdios florais são formados por espigueta, dependendo de sua posição na espiga. Desses, quatro a cinco são viabilizados e podem ser fertilizados na antese (Kirby, 1988).

Maior duração de alongamento do colmo - da iniciação da espigueta terminal até a antese - pode resultar em rendimento potencial superior, refletido no aumento de massa de matéria seca da espiga e no número de flores férteis na antese. Entretanto, não se sabe claramente quais processos estão envolvidos no aumento da matéria seca da espiga, e se esta variável pode explicar exatamente o número de flores férteis e, consequentemente, de grãos por unidade de área, quando a duração do subperíodo de elongação do colmo for modificada por efeito de fotoperíodo, conforme constatado por González et al. (2003a, 2003b, 2005a, 2005b). Ao avaliar o impacto do fotoperíodo estendido, durante a elongação do colmo em trigo, Serrago et al. (2008) constataram que o número de flores férteis é mediado pelo suprimento de assimilados, disponibilizado para o desenvolvimento das flores.

A sensibilidade ao fotoperíodo, parece dar-se de forma relativamente independente nas diferentes fases de desenvolvimento, e cada genótipo responde de modo diferente ao comprimento do dia. Em decorrência disso, a duração da fase vegetativa e o final da fase reprodutiva podem ser manipulados independentemente, para elevar o rendimento potencial de grãos em trigo (Slafer et al., 2001; Whitechurch \& Slafer, 2001), via controle exercido pelos genes Ppd-D1 e Ppd-B1 (González et al., 2005c). Pouco se sabe sobre o efeito da vernalização, durante a fase reprodutiva. Ainda não se entende bem se no trigo a vernalização pode influenciar a duração da etapa final da fase reprodutiva, em condições de campo. Porém, conforme Herndl et al.
(2008), a duração das fases vegetativa e reprodutiva (germinação/emergência até a antese) é condicionada por grupos de genes relacionados às exigências de vernalização (Vrn), sensibilidade ao fotoperíodo (Ppd) e precocidade intrínseca (Eps), que determinam as diferenças no desenvolvimento (taxa e ciclo), e que é observada entre cultivares distintas e entre trigos de primavera e de inverno.

O objetivo deste trabalho foi avaliar o efeito do fotoperíodo e da vernalização sobre o desenvolvimento fenológico de cinco cultivares brasileiras de trigo.

\section{Material e Métodos}

$\mathrm{O}$ experimento foi realizado na área experimental da Embrapa Trigo, em Passo Fundo, RS, a $28^{\circ} 15^{\prime} \mathrm{S}$, $52^{\circ} 24^{\prime} \mathrm{W}$ e $687 \mathrm{~m}$ de altitude. As temperaturas médias mensais do ar estão apresentadas na Figura 1. O solo da área experimental é classificado como Latossolo Vermelho distrófico típico, de textura argilosa, com relevo suave ondulado a ondulado (Sistema brasileiro de classificação de solos, 1999).

O delineamento experimental foi o de blocos ao acaso, com quatro repetições, com os tratamentos dispostos em parcelas subsubdivididas. Foram empregados três regimes fotoperiódicos: fotoperíodo natural (FN), fotoperíodo estendido em 4 horas (FN 4) e fotoperíodo estendido até completar 20 horas de luz (FE 20), locados nas parcelas principais; dois regimes de vernalização: vernalizado (V) e não vernalizado (NV), dispostos nas subparcelas; e cinco cultivares de trigo, testadas nas subsubparcelas: BRS 179, BRS 194, BRS Figueira, BRS Umbu e BRS 207.

O experimento foi instalado em três épocas de semeadura: 23 de junho - dentro do período indicado

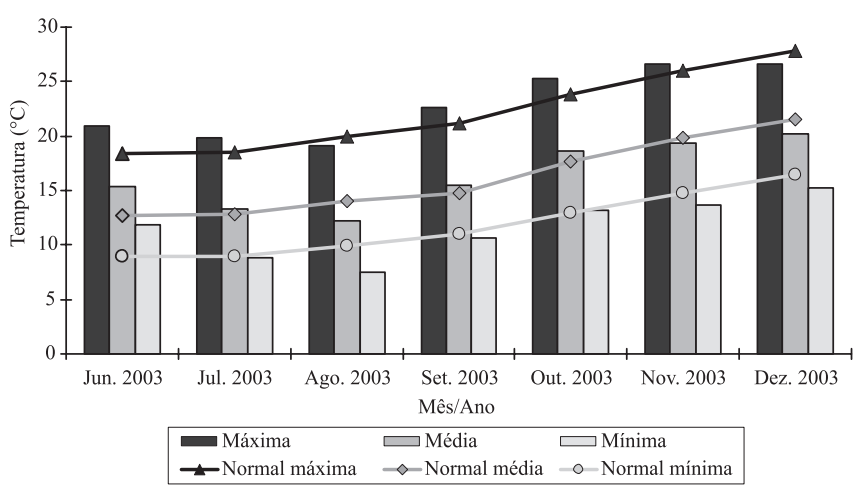

Figura 1. Temperaturas médias mensais de junho a dezembro de 2003, em Passo Fundo, RS. 
pela Comissão Sul-Brasileira de Pesquisa de Trigo (Reunião da Comissão Sul-Brasileira de Pesquisa de Trigo, 2003) -, 25 de julho e 27 de agosto de 2003 (após a época indicada). Cada unidade experimental (subsubparcela) foi composta por cinco linhas de $5 \mathrm{~m}$ de comprimento, espaçadas em 0,20 m, com área total de $5 \mathrm{~m}^{2}$. Como bordadura, foram consideradas as duas linhas externas da subsubparcela e $0,5 \mathrm{~m}$ em cada extremidade das linhas, com área útil total de $2,4 \mathrm{~m}^{2}$.

A adubação de semeadura foi realizada de acordo com o resultado da análise de solo. Para suprir a necessidade de nutrientes, foram aplicados $200 \mathrm{~kg} \mathrm{ha}^{-1}$ de adubo da fórmula 5-20-20 (N-P-K) e $154 \mathrm{~kg} \mathrm{ha}^{-1}$ de ureia em cobertura no afilhamento, para atender a necessidade em nitrogênio, conforme as indicações da Comissão Sul-Brasileira de Pesquisa de Trigo (Reunião da Comissão Sul-Brasileira de Pesquisa de Trigo, 2003). $\mathrm{O}$ experimento foi implantado em área manejada sob sistema de plantio direto com a soja (Glycine max (L.) Merr.) como cultura antecessora (com 4,6 $\mathrm{Mg} \mathrm{ha}^{-1}$ de matéria seca em cobertura, na semeadura do trigo).

As sementes com vernalização foram tratadas com fungicidas indicados para a cultura de trigo e colocadas em germinador com temperatura em torno de $4^{\circ} \mathrm{C}$, por 30 dias (antes da semeadura), em papel de germinação umedecido. As sementes do tratamento não vernalizado foram tratadas com os mesmos fungicidas e colocadas em germinador a $20^{\circ} \mathrm{C}$ ( 48 horas antes da semeadura), em papel de germinação umedecido, para que no momento da semeadura tivessem o mesmo desenvolvimento inicial que as sementes do tratamento vernalizado.

Para os tratamentos de suplementação fotoperiódica, foram utilizadas estruturas de iluminação artificial, compostas por caibros de madeira, e suporte para lâmpadas colocadas a 1,80 m de altura do solo. Foram utilizados anteparos de metal, acoplados aos suportes das lâmpadas, para direcionar a luz sobre as parcelas que receberam os tratamentos e para evitar sua incidência sobre as outras parcelas. Foram utilizadas lâmpadas mistas de $160 \mathrm{~W}$.

A suplementação luminosa era acionada automaticamente por temporizador, que controlavam as lâmpadas instaladas em cada parcela principal. Para determinar o horário em que o sistema era acionado e desligado, foram tomados como referência o nascer e pôr do sol em Passo Fundo, pelo horário oficial brasileiro.
Os tratos culturais foram realizados de acordo com as indicações da Comissão Sul-Brasileira de Pesquisa de Trigo (Reunião da Comissão Sul-Brasileira de Pesquisa de Trigo, 2003).

Foram avaliados os seguintes estádios de desenvolvimento: emergência (EME), duplo anel (DA), espigueta terminal (ET), antese (ANT) e maturação fisiológica (MF). Para avaliação do duplo anel e da espigueta terminal, foram coletadas aleatoriamente três plantas por parcela, a cada dois dias, para acompanhar o desenvolvimento dos primórdios reprodutivos, conforme Nerson et al. (1980). Para os demais estádios, foi feita a avaliação visual a cada dois dias, tendo-se estipulado pleno desenvolvimento quando mais de $50 \%$ das plantas encontravam-se no estádio avaliado, e tendo-se como referência a escala de desenvolvimento de Feekes-Large (Mundstock, 1998). A análise estatística foi realizada pela análise de variância (ANOVA), e a comparação das médias dos tratamentos foi efetuada pelo teste de Tukey, a 5\% de probabilidade.

\section{Resultados e Discussão}

Houve interação significativa entre fotoperíodo e cultivar nas plantas com época de semeadura em 23/6 (Tabela 1). As cultivares BRS 179 e BRS Umbu tiveram o seu ciclo reduzido, quando o fotoperíodo foi estendido, tanto para FN 4 quanto para FE 20. A explicação para esses resultados é que o fotoperíodo pode acelerar o desenvolvimento da planta de trigo e esse adiantamento é altamente dependente da sensibilidade do genótipo ao fotoperíodo (Ritchie, 1991).

Analisando-se os subperíodos de desenvolvimento da cultivar BRS 179 (Figura 2 A), em relação à época de semeadura em 23/6, observa-se que o ciclo foi levemente reduzido com a vernalização, em cada fotoperíodo analisado. Essa resposta devese, provavelmente, ao baixo grau de sensibilidade desse genótipo a temperaturas vernalizantes. Quanto ao fotoperíodo, essa cultivar teve o seu ciclo, comparativamente ao $\mathrm{FN}$, diminuído com o acréscimo de horas de luz. González et al. (2002) obtiveram resultados semelhantes, que mostraram respostas de redução do tempo - da semeadura ao espigamento quando o fotoperíodo foi aumentado. No fotoperíodo estendido, o subperíodo mais sensível à vernalização foi o do alongamento do colmo, que vai deste à formação 
da espigueta terminal e à antese; e o menos afetado foi o período da emergência ao duplo anel. Esses resultados diferem de outros relatados na literatura, que mostram que a vernalização afeta o período que vai da semeadura até a espigueta terminal, sem interferência sobre o alongamento do colmo (Slafer \& Whitechurch, 2001).

Quanto ao FN - épocas de semeadura 23/6 e 27/8 (Figura $2 \mathrm{~A}$ e C) -, houve pequena resposta à vernalização, efeito esse que não foi visível na época 25/7 (Figura 2 B). Resultados semelhantes foram obtidos por Davidson et al. (1985), ao analisar as respostas da taxa de desenvolvimento de 117 genótipos ao fotoperíodo e à vernalização. Concluíram que algumas cultivares não responderam à vernalização, quando submetidas a fotoperíodo curto, ou seja, sementes com e sem vernalização levaram o mesmo tempo para alcançar o espigamento.

Tabela 1. Duração de ciclo - dias da emergência até a maturação fisiológica - de cinco cultivares de trigo, em diferentes épocas das semeaduras: 23/6/2003, 25/7/2003 e 27/8/2003, em função de fotoperíodo ${ }^{(1)}$.

\begin{tabular}{|c|c|c|c|c|}
\hline \multirow[t]{2}{*}{ Cultivar } & \multicolumn{3}{|c|}{ Fotoperíodo } & \multirow[t]{2}{*}{ Média } \\
\hline & FN & FN 4 & FE 20 & \\
\hline \multicolumn{5}{|c|}{$23 / 6 / 2003$} \\
\hline BRS 179 & $120 \mathrm{Ab}$ & $106 \mathrm{Bb}$ & $104 \mathrm{c}$ & 110 \\
\hline BRS 194 & $120 \mathrm{Ab}$ & $116 \mathrm{ABa}$ & $115 b$ & 117 \\
\hline BRS 207 & $114 \mathrm{Ac}$ & $108 \mathrm{ABb}$ & $104 \mathrm{Bc}$ & 108 \\
\hline BRS Figueira & $132 \mathrm{Aa}$ & $123 \mathrm{Aa}$ & $126 \mathrm{Aa}$ & 127 \\
\hline$\underline{\text { BRS Umbu }}$ & $129 \mathrm{Aa}$ & $119 \mathrm{Ba}$ & $116 \mathrm{Bb}$ & 121 \\
\hline Média & 123 & 115 & 113 & \\
\hline $\mathrm{CV}(\%)$ & & 3,33 & & \\
\hline \multicolumn{5}{|c|}{$25 / 7 / 2003$} \\
\hline BRS 179 & $111 \mathrm{Abc}$ & $102 \mathrm{Bc}$ & $101 \mathrm{Bc}$ & 104 \\
\hline BRS 194 & 109Acd & $106 \mathrm{Bb}$ & $104 \mathrm{Bb}$ & 106 \\
\hline BRS 207 & 107Ad & $102 \mathrm{Bc}$ & $95 \mathrm{Cd}$ & 101 \\
\hline BRS Figueira & $114 \mathrm{Aab}$ & $114 \mathrm{Ba}$ & $111 \mathrm{Ba}$ & 113 \\
\hline BRS Umbu & $118 \mathrm{Aa}$ & $112 \mathrm{Ba}$ & $109 \mathrm{Ba}$ & 113 \\
\hline Média & 112 & 107 & 104 & \\
\hline \multirow{2}{*}{\multicolumn{5}{|c|}{$\frac{1,58}{27 / 8 / 2003}$}} \\
\hline & & & & \\
\hline BRS 179 & $86 \mathrm{Ac}$ & $82 \mathrm{Bc}$ & $79 \mathrm{Cc}$ & 82 \\
\hline BRS 194 & $91 \mathrm{Ab}$ & $91 \mathrm{Ab}$ & $88 \mathrm{Ab}$ & 90 \\
\hline BRS 207 & $88 \mathrm{Abc}$ & $80 \mathrm{Bc}$ & $78 \mathrm{Bc}$ & 82 \\
\hline BRS Figueira & $101 \mathrm{Aa}$ & $100 \mathrm{Aa}$ & $94 \mathrm{Ba}$ & 98 \\
\hline BRS Umbu & 99Aa & $93 \mathrm{ABb}$ & $92 \mathrm{Bab}$ & 95 \\
\hline Média & 92 & 89 & 86 & \\
\hline CV (\%) & & 2,4 & & \\
\hline
\end{tabular}

(1)Médias seguidas de letras iguais, maiúsculas na linha e minúsculas na coluna, não diferem entre si pelo teste de Tukey, a 5\% de probabilidade. FN, fotoperíodo natural; FN 4, fotoperíodo estendido em mais 4 horas; FE 20, fotoperíodo fixo de 20 horas; CV, coeficiente de variação.
$\mathrm{Na}$ cultivar BRS Umbu, na época 23/6 (Figura 3), houve maior resposta à vernalização na fase reprodutiva, independentemente do comprimento do dia (no FN 4 e FE 20, o efeito da vernalização foi bastante acentuado no subperíodo de DA a ET). Esse resultado difere dos de alguns autores (Ritchie, 1991; Slafer \& Whitechurch, 2001), que ressaltam a influência de temperaturas vernalizantes apenas na fase vegetativa. $\mathrm{O}$ efeito da vernalização, no início da fase reprodutiva, é pouco mencionado, não tendo sido ainda comprovado o grau de influência sobre essa fase. Uma diferença marcante, nessa cultivar, foi a influência do fotoperíodo sobre os subperíodos de DA a ET. Esse tipo de resultado é
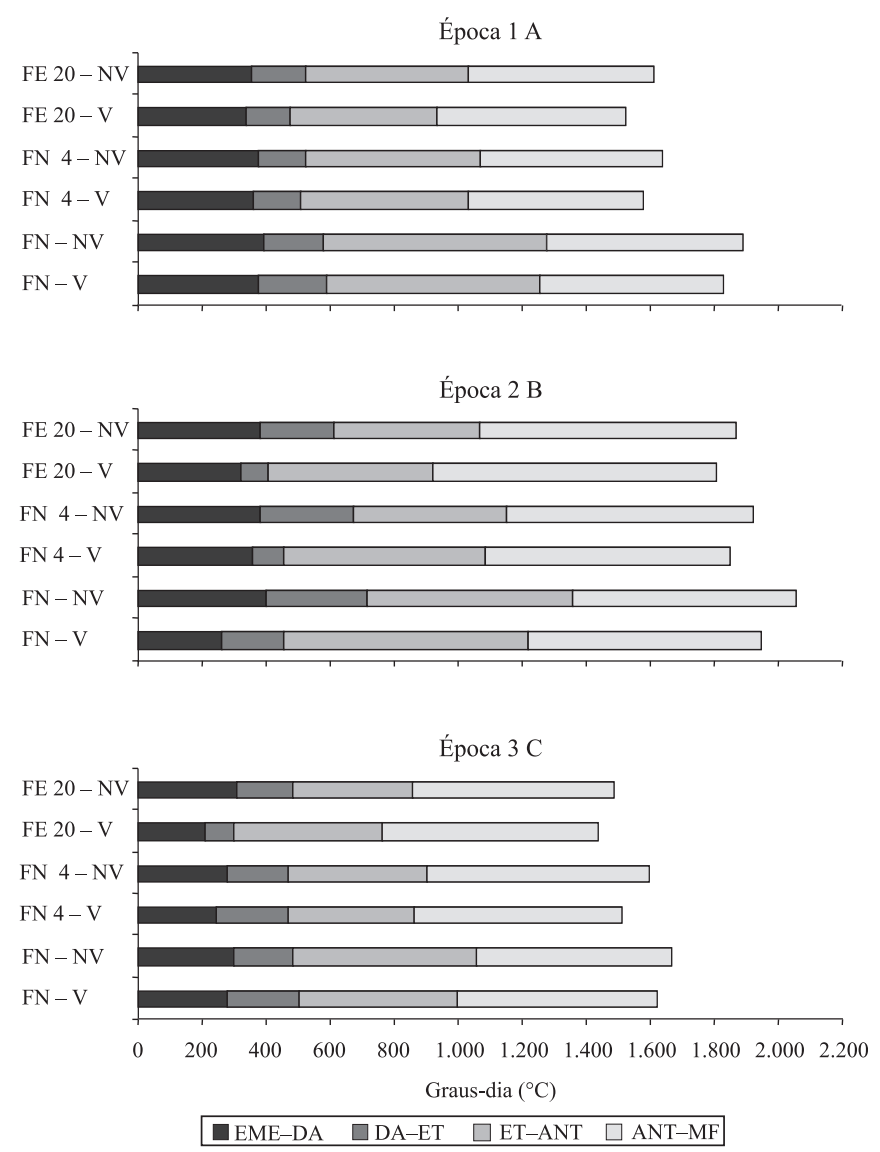

Figura 2. Duração dos subperíodos de desenvolvimento da cultivar de trigo BRS 179 (graus-dia acima de $0{ }^{\circ} \mathrm{C}$ ), em função das épocas de semeadura: 23/6, 25/7 e 27/8 e tratamentos de fotoperíodo e vernalização. $\mathrm{FN}$, fotoperíodo natural; $\mathrm{FN} \mathrm{4}$, fotoperíodo estendido em mais quatro horas; FE 20, fotoperíodo fixo em 20 horas; NV, não vernalizado; $\mathrm{V}$, vernalizado; EME, emergência; DA, duplo anel; ET, espigueta terminal; ANT, antese; e MF, maturação fisiológica. 
destacado por Slafer \& Rawson (1994), que afirmam existir influência do fotoperíodo no início da fase reprodutiva.

Para as cultivares BRS 194 e BRS 207, houve diferença quando o fotoperíodo natural (FN) foi estendido para 20 horas (FE 20) (Tabela 1). Na cultivar BRS 194 (Figura 4 A), houve pouca diferença nos subperíodos de desenvolvimento (época 23/6), quando o fotoperíodo foi estendido em FN 4 e FE 20 , com resposta mais acentuada no encurtamento do subperíodo de espigueta terminal à antese. A fase de enchimento de grãos não apresentou diferença, o que
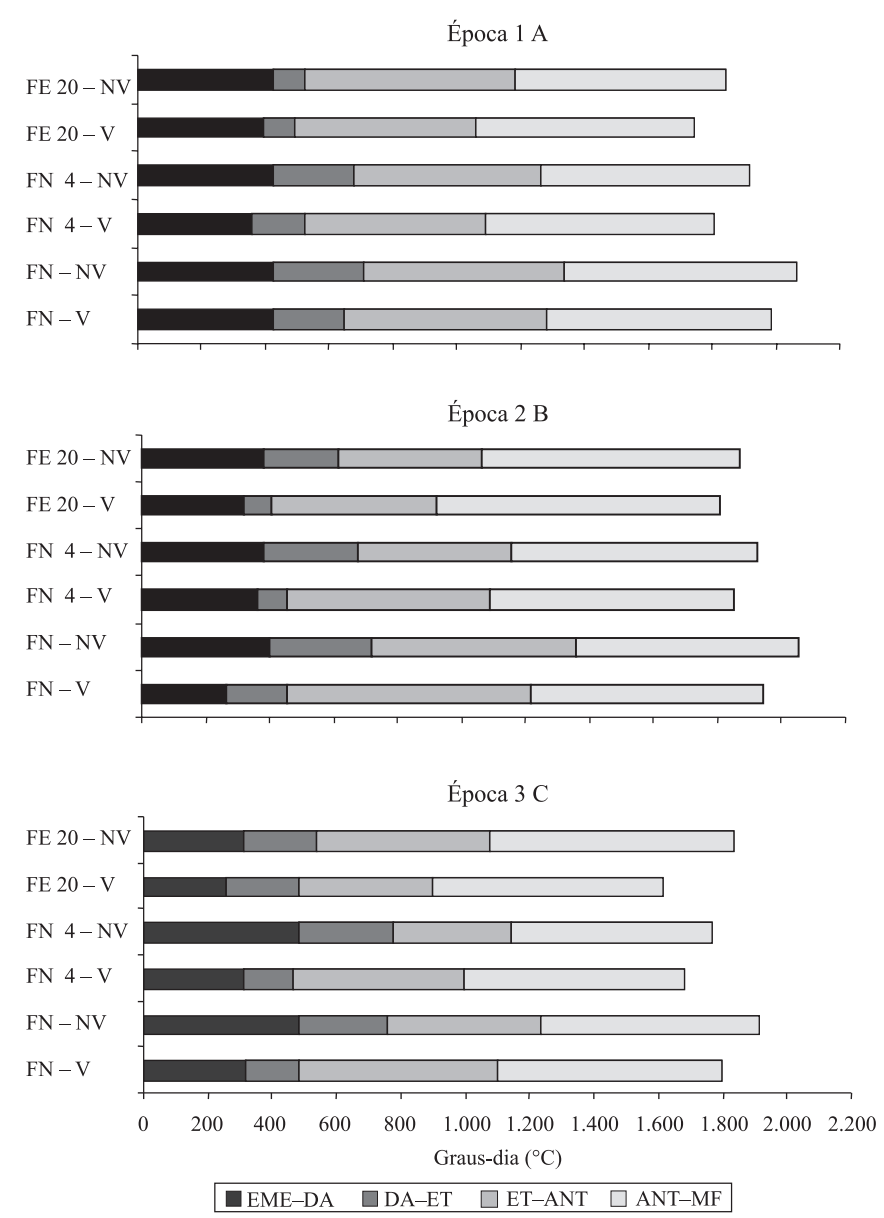

Figura 3. Duração dos subperíodos de desenvolvimento da cultivar de trigo BRS Umbu (graus-dia acima de $0^{\circ} \mathrm{C}$ ), em função das épocas de semeadura (23/6, 25/7 e 27/8) e tratamentos de fotoperíodo e vernalização. FN, fotoperíodo natural; FN 4, fotoperíodo estendido em mais quatro horas; FE 20, fotoperíodo fixo em 20 horas; NV, não vernalizado; $\mathrm{V}$, vernalizado; EME, emergência; DA, duplo anel; ET, espigueta terminal; ANT, antese; e MF, maturação fisiológica. confirma a ideia de que essa fase é afetada somente pela temperatura (Slafer \& Whitechurch, 2001).

$\mathrm{Na}$ cultivar BRS 207 (época 23/6), o subperíodo da emergência ao duplo anel foi bastante influenciado pela vernalização no FN 4 e FE 20. O final da fase reprodutiva e o tempo para completar o ciclo total foram reduzidos pela vernalização, à medida que se aumentou o fotoperíodo (Figura 5).

A cultivar BRS Figueira não teve o ciclo influenciado pelo fotoperíodo (Tabela 1). Nessa cultivar, o subperíodo de duplo anel à espigueta terminal foi influenciado pela vernalização (Figura 6).
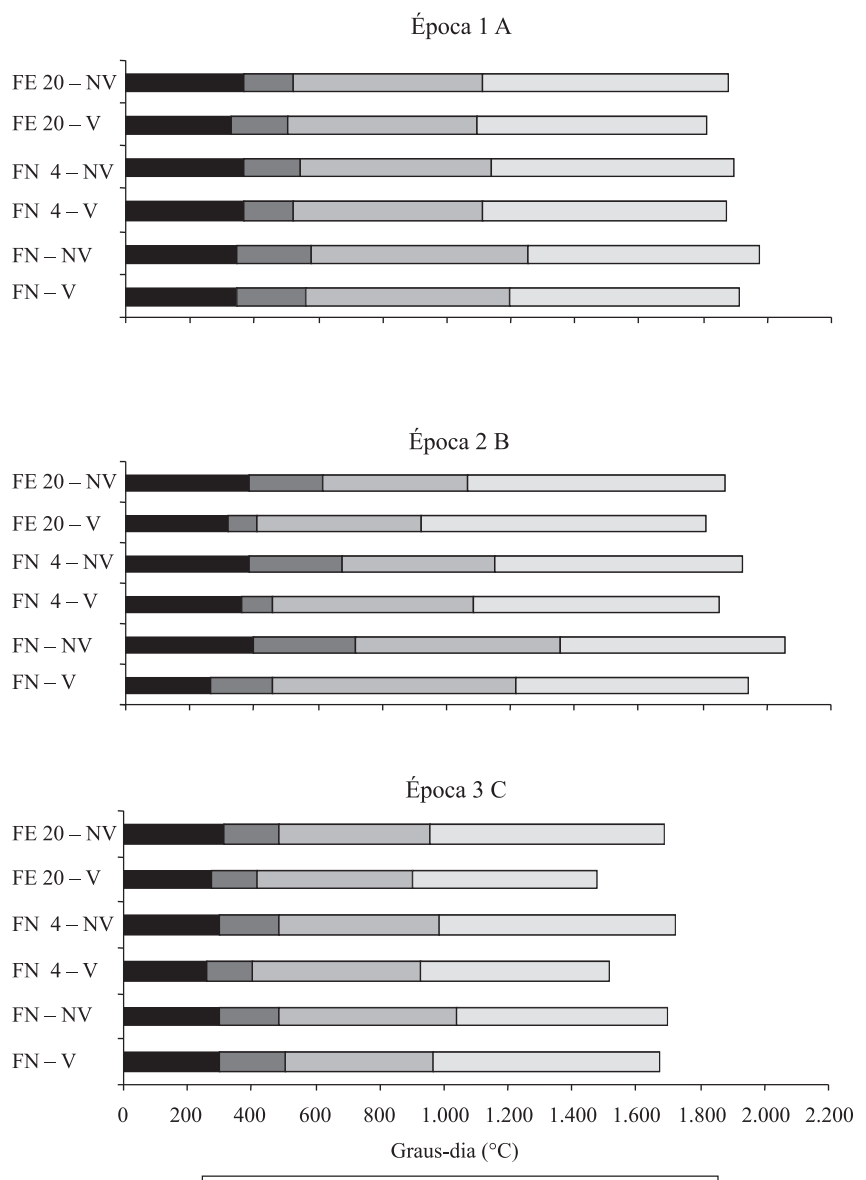
EME-DA $\quad \square$ DA-ET $\square$ ET-ANT $\square$ ANT-MF

Figura 4. Duração dos subperíodos de desenvolvimento da cultivar de trigo BRS 194 (graus-dia acima de $0^{\circ} \mathrm{C}$ ), em função das épocas de semeadura $(23 / 6,25 / 7$ e 27/8) e tratamentos de fotoperíodo e vernalização. FN, fotoperíodo natural; FN 4, fotoperíodo estendido em mais quatro horas; FE 20, fotoperíodo fixo em 20 horas; NV, não vernalizado; $\mathrm{V}$, vernalizado; EME, emergência; DA, duplo anel; ET, espigueta terminal; ANT, antese; e MF, maturação fisiológica.

Pesq. agropec. bras., Brasília, v.44, n.11, p.1383-1390, nov. 2009 
Houve interação significativa, em relação a épocas $25 / 7$ e $27 / 8$, tanto para fotoperíodo e cultivar quanto para vernalização e cultivar (Tabelas 1 e 2).

Na época 25/7, as cultivares BRS 179, BRS 194, BRS Figueira e BRS Umbu tiveram o ciclo encurtado com o aumento do fotoperíodo natural (FN), entretanto, sem diferença entre FN 4 e FE 20 (Tabela 1). A cultivar BRS 207 teve redução progressiva no ciclo com o aumento no fotoperíodo. Na época 25/7, as cultivares BRS 179, BRS 194 e BRS 207 não apresentaram diferenças significativas em resposta à vernalização (Tabela 2). Na BRS Figueira e na BRS Umbu, a vernalização encurtou o ciclo, o que
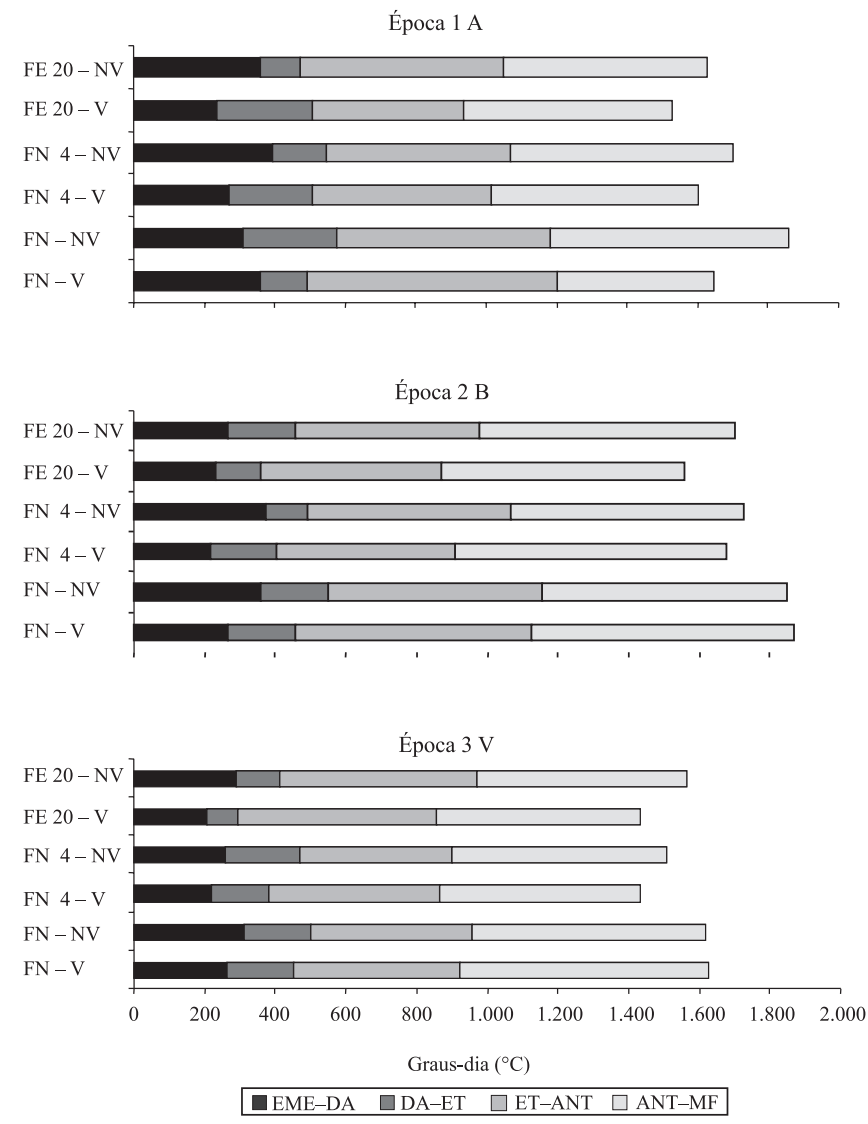

Figura 5. Duração dos subperíodos de desenvolvimento da cultivar de trigo BRS 207 (graus-dia acima de $0^{\circ} \mathrm{C}$ ), em função das épocas de semeadura (23/6, 25/7 e 27/8) e tratamentos de fotoperíodo e vernalização. $\mathrm{FN}$, fotoperíodo natural; $\mathrm{FN} \mathrm{4}$, fotoperíodo estendido em mais quatro horas; FE 20, fotoperíodo fixo em 20 horas; NV, não vernalizado; $\mathrm{V}$, vernalizado; EME, emergência; DA, duplo anel; ET, espigueta terminal; ANT, antese; e MF, maturação fisiológica.

Pesq. agropec. bras., Brasília, v.44, n.11, p.1383-1390, nov. 2009 mostra que essas cultivares são mais sensíveis à vernalização do que as outras testadas.

$\mathrm{Na}$ época 27/8, a cultivar BRS 179 teve o ciclo acelerado com o aumento do fotoperíodo. A cultivares BRS 194 e BRS 207 não apresentaram resposta com a mudança do fotoperíodo. A cultivar BRS Figueira respondeu ao fotoperíodo somente quando foi estendido a 20 horas de luz. A BRS Umbu apresentou diferença no ciclo para FN a FE 20. Na época 27/8, com temperaturas ambientais mais elevadas (Tabela 2), as cultivares BRS 179, BRS 207 e BRS Figueira não apresentaram diferenças significativas com a vernalização, enquanto as cultivares BRS 194 e BRS Umbu tiveram o ciclo encurtado. Em relação
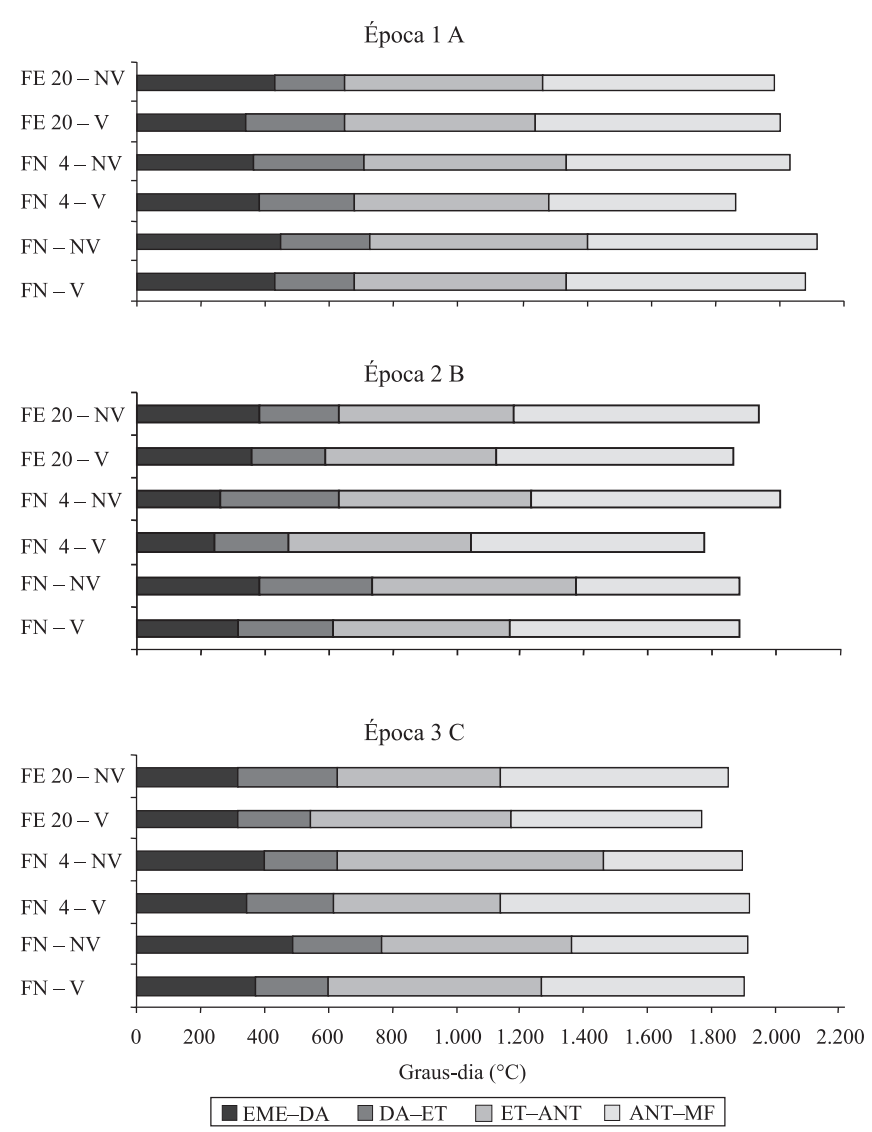

Figura 6. Duração dos subperíodos de desenvolvimento da cultivar de trigo BRS Figueira (graus-dia acima de $0^{\circ} \mathrm{C}$ ), em função das épocas de semeadura (23/6, 25/7 e 27/8) e tratamentos de fotoperíodo e vernalização. FN, fotoperíodo natural; FN 4, fotoperíodo estendido em mais quatro horas; FE 20, fotoperíodo fixo em 20 horas; NV, não vernalizado; V, vernalizado; EME, emergência; DA, duplo anel; ET, espigueta terminal; ANT, antese; e MF, maturação fisiológica. 
às épocas $25 / 7$ e $27 / 8$, a duração da fase vegetativa diminuiu com a vernalização artificial em todos os fotoperíodos. Essa resposta confirma o maior efeito da vernalização sobre a fase vegetativa, conforme Slafer \& Whitechurch (2001); embora, no presente trabalho, tenha sido constatado efeito da vernalização também na fase reprodutiva. Na época $25 / 7$, houve interação com o fotoperíodo com decréscimo na duração dessa fase com o aumento do dia. A duração do final da fase reprodutiva foi fortemente reduzida pela vernalização, quando o fotoperíodo foi estendido (FN 4 e FE 20) (Figura 3). O comprimento deste subperíodo afeta diretamente o número de grãos por espiga, se essa etapa for encurtada, e pode haver também diminuição no número de espiguetas por espiga, conforme Slafer \& Whitechurch (2001), e consequentemente, no rendimento de grãos.

Os componentes do regime térmico (temperatura média das máximas, temperatura média e temperatura média das mínimas, bem como seus respectivos valores normais), para o período junho a dezembro de 2003, estão mostrados na Figura 1. Os resultados deste trabalho reforçam a hipótese de que é possível a manipulação independente da duração de fases/ subperíodos críticos do desenvolvimento em trigo,

Tabela 2. Duração de ciclo - dias da emergência até a maturação fisiológica - de cinco cultivares de trigo nas épocas de semeadura: 25/7/2003 e 27/8/2003, em razão da vernalização $^{(1)}$.

\begin{tabular}{|c|c|c|c|}
\hline \multirow[t]{2}{*}{ Cultivar } & \multicolumn{2}{|c|}{ Vernalização } & \multirow[t]{2}{*}{ Média } \\
\hline & NV & $\mathrm{V}$ & \\
\hline \multicolumn{4}{|c|}{$25 / 7 / 2003$} \\
\hline BRS 179 & $105 \mathrm{Ab}$ & $103 \mathrm{Abc}$ & 104 \\
\hline BRS 194 & $107 \mathrm{Ab}$ & $106 \mathrm{Ab}$ & 107 \\
\hline BRS 207 & $103 \mathrm{Ab}$ & 99Ac & 101 \\
\hline BRS Figueira & $115 \mathrm{Aa}$ & $113 \mathrm{Aa}$ & 113 \\
\hline BRS Umbu & $115 \mathrm{Aa}$ & $110 \mathrm{Aa}$ & 113 \\
\hline Média & 109 & 106 & \\
\hline C V $(\%)$ & & & \\
\hline \multicolumn{4}{|c|}{$27 / 8 / 2003$} \\
\hline BRS 179 & $83 \mathrm{Ac}$ & $81 \mathrm{Ac}$ & 82 \\
\hline BRS 194 & $91 \mathrm{Ab}$ & $88 \mathrm{Bb}$ & 90 \\
\hline BRS 207 & $83 \mathrm{Ac}$ & 81Ac & 82 \\
\hline BRS Figueira & 99Aa & 97Aa & 98 \\
\hline BRS Umbu & 97Aa & $92 \mathrm{Bb}$ & 95 \\
\hline Média & 91 & 88 & \\
\hline $\mathrm{CV}(\%)$ & \multicolumn{2}{|c|}{2,4} & \\
\hline
\end{tabular}

${ }^{(1)}$ Médias seguidas de letras iguais maiúsculas, na linha, minúsculas, na coluna, não diferem entre si pelo teste de Tukey, a 5\% de probabilidade. $\mathrm{NV}$, não vernalizado; $\mathrm{V}$, vernalizado; $\mathrm{CV}$, coeficiente de variação. especialmente em relação à resposta ao fotoperíodo na etapa reprodutiva, para a elevação do potencial de rendimento da cultura (Slafer et al., 2001).

Nas três épocas em que foi realizado o experimento, verificou-se que o ciclo da cultura foi encurtado pelo aumento do fotoperíodo. Este trabalho, em condições de campo, mostrou fortes indícios do efeito da vernalização também na etapa inicial da fase reprodutiva (imediatamente após a formação do duplo anel, quando os primórdios florais começam a se diferenciar). Esse fato contraria as principais teorias de resposta à vernalização em trigo, que destacam esse tipo de efeito como condicionado apenas à fase vegetativa, conforme descrevem, por exemplo, Slafer \& Whitechurch (2001). Embora a sensibilidade à vernalização em trigo seja considerada restrita à fase vegetativa e, quando muito, ao início da fase reprodutiva, González et al. (2002) encontraram resposta à vernalização no final da fase reprodutiva. Whitechurch et al. (2007) ampliaram esse tipo de estudo e discutiram que a etapa final da fase reprodutiva em trigo é insensível á vernalização, com respostas, nessa etapa, muito menores que as obtidas em fases anteriores. A efetiva comprovação experimental dessa resposta, nos trigos brasileiros, vai requerer estudos adicionais com os genótipos testados, em que se deve buscar contornar efeitos de interações não controladas, como a de temperatura e fotoperíodo, que podem ter influenciado o tipo de resposta obtida.

\section{Conclusões}

1. Há resposta à vernalização na fase reprodutiva do trigo, particularmente na etapa inicial - duplo anel até início de formação da espigueta terminal -, dependentemente do genótipo.

2. O fotoperíodo influencia a taxa de desenvolvimento e a duração do ciclo do trigo, independentemente do processo de vernalização.

3. A vernalização influencia a taxa de desenvolvimento da fase vegetativa do trigo, independentemente da resposta ao fotoperíodo.

4. A resposta ao fotoperíodo, na fase reprodutiva do trigo, é dependente do genótipo.

\section{Referências}

DAVIDSON, J.L.; CHRISTIAN, K.R.; JONES, D.B.; BREMNER, P.M. Responses of wheat to vernalization and photoperiod. Australian Journal of Agricultural Research, v.36, p.347-359, 1985. 
FISCHER, R.A. Number of kernels in wheat crops and the influence of solar radiation and temperature. Journal of Agricultural Science, v.100, p.447-461, 1985.

GONZÁLEZ, F.G.; SLAFER, G.A.; MIRALLES, D.J. Floret development and spike growth as affected by photoperiod during stem elongation in wheat. Field Crops Research, v.81, p.29-38, 2003a.

GONZÁlEZ, F.G.; SLAFER, G.A.; MIRALlES, D.J. Floret development and survival in wheat plants exposed to contrasting photoperiod and radiation environments during stem elongation. Functional Plant Biology, v.32, p.189-197, 2005a.

GONZÁLEZ, F.G.; SLAFER, G.A.; MIRALLES, D.J. Grain and floret number in response to photoperiod during stem elongation in fully and slightly vernalized wheats. Field Crops Research, v.81, p.17-27, 2003b.

GONZÁLEZ, F.G.; SLAFER, G.A.; MIRALLES, D.J. Photoperiod during stem elongation in wheat: is its impact on fertile floret and grain number determination similar to that of radiation? Functional Plant Biology, v.32, p.181-188, 2005b.

GONZÁLEZ, F.G.; SLAFER, G.A.; MIRALLES, D.J. Pre-anthesis development and number of fertile florets in wheat as affected by photoperiod sensitivity genes Ppd-D1 and Ppd-B1. Euphytica, v.146, p.253-269, 2005c.

GONZÁLEZ, F.G.; SLAFER, G.A.; MIRALLES, D.J. Vernalization and photoperiod responses during wheat pre-flowering reproductive phases. Field Crops Research, v.74, p.183-195, 2002.

HERNDL, M.; WHITE, J.W.; HUNT, L.A.; GREAEFF, S.; CLAUPEIN, W. Field-based evaluation of vernalization requirement photoperiod response and earliness per se in bread wheat (Triticum aestivum L.). Field Crops Research, v.105, p.193-201, 2008.

KIRBY, E.J.M. Analysis of leaf, stem and ear growth in wheat from terminal spikelet stage to anthesis. Fiel Crops Research, v.18, p.127-140, 1988.

MUNDSTOCK, C.M. Planejamento e manejo integrado da lavoura de trigo. Porto Alegre: Ed. do Autor, 1998. 228p.

NERSON, H.; SIBONY, M.; PINTHUS, M.J. Short communications - a scale for the assessment of the developmental stages of the wheat (Triticum aestivum L.) spike. Annals of Botany, v.45, p.203-204, 1980.
REUNIÃO DA COMISSÃO SUL-BRASILEIRA DE PESQUISA DE TRIGO, 35., 2003, Passo Fundo. Indicações técnicas da Comissão Sul-brasileira de Pesquisa de Trigo. Passo Fundo: Embrapa Trigo, 2003. 120p.

RITCHIE, J.T. Wheat phasic development. In: HANKS J.; RITCHIE, J.T. (Ed.). Modeling plant and soil systems. Madison: American Society of Agronomy, 1991. p.31-54. (Agronomy monograph, 31).

SERRAGO, R.A.; MIRALLES, D.J.; SLAFER, G.A. Floret fertility in wheat as affected by photoperiod during stem elongation and removal of spikelets at booting. European Journal of Agronomy, v.28, p.301-308, 2008.

SISTEMA brasileiro de classificação de solos. Brasília: Embrapa Produção de Informação; Rio de Janeiro: Embrapa Solos, 1999. 412p.

SLAFER, G.A. Differences in phasic development rate amongst wheat cultivars independent of responses to photoperiod and vernalization. A viewpoint of the intrinsic earliness hypothesis. Journal of Agricultural Science, v.126, p.403-419, 1996.

SLAFER, G.A.;ABELEDO, L.G.; MIRALLES, D.J.; GONZÁLEZ, F.G.; WHITECHURCH, E.M. Photoperiod sensitivity during stem elongation as an avenue to rise potential yield in wheat. Euphytica, v.119, p.191-197, 2001.

SLAFER, G.A.; RAWSON, H.M. Sensitivity of wheat phasic development to major environmental factors: a re-examination of some assumptions made by physiologists and modellers. Australian Journal of Plant Physiology, v.21, p.393-426, 1994.

SLAFER, G.A.; WHITECHURCH, E.M. Manipulating wheat development to improve adaptation. In: REYNOLDS, M.P.; ORTIZ-MONASTERIO, J.I.; MCNAB, A. (Ed.). Application of physiology in wheat breeding. México: CIMMYT, 2001. p.160-170.

WHITECHURCH, E.M.; SLAFER, G.A. Responses to photoperiod before and after jointing in wheat substitution lines. Euphytica, v.118, p.47-51, 2001.

WHITECHURCH, E.M.; SLAFER, G.A.; MIRALLES, D.J. Variability in the duration of stem elongation in wheat genotypes and sensitivity to photoperiod and vernalization. Journal of Agronomy and Crop Science, v.193, p.131-137, 2007.

Recebido em 10 de fevereiro de 2009 e aprovado em 29 de outubro de 2009 